\title{
О.В. Желева
}

\section{ОГЛАШЕНИЕ ПОКАЗАНИЙ КАК ВОЗМОЖНОСТЬ ЗЛОУПОТРЕБЛЕНИЯ СУДОМ ДИСКРЕЦИОННЫМИ ПОЛНОМОЧИЯМИ}

\begin{abstract}
Рассматривается институт оглашения показаний потерпевшего, свидетеля с точки зрения достижения назначения уголовного судопроизводства, соблюдения принципов состязательности и равноправия сторон. На основе анализа Постановлений ЕСПЧ, а также российской судебной практики приводятся случаи, когда оглашение показаний становится способом злоупотребления судом дискреционными полномочиями. В результате исследования автором предложены критерии законности и обоснованности оглашения показаний.
\end{abstract}

Ключевые слова: уголовное судопроизводство, участники уголовного прочесса, оглашение показаний, злоупотребление дискрецииоными полномочиями.

Одним из основных принципов осуществления правосудия является принцип состязательности, закрепленный в ч. 3 ст. 123 Конституции Российской Федерации. Вслед за Конституцией РФ принцип состязательности нашел свое отражение и в ст. 15 Уголовно-процессуального кодекса РФ.

М.С. Строгович определял состязательность следующим образом: «Это такое построение судебного разбирательства, при котором обвинение отделено от суда, обвинение и защита осуществляются равноправными сторонами, а функция суда состоит в разрешении дела» $[1$, c. 149]. Применительно к уголовному судопроизводству аналогичное определение принципа состязательности содержится и в ряде постановлений Конституционного Суда РФ. Например, в Постановлении от 29 июня 2004 г. № 13-П по делу о проверке конституционности отдельных положений ст.ст. 7, 15, 107, 234 и 450 УПК Российской Федерации Конституционный Суд РФ указал, что функция разрешения уголовного дела отделена от функций обвинения и защиты, и осуществление каждой из них возлагается на различные субъекты уголовного судопроизводства, обладающие равными процессуальными правами. [2] Стороны обвинения и защиты в условиях состязательности должны действовать таким образом, чтобы использовать предоставленные им права и исполнить возложенные на них обязанности без нарушения закона, прав и законных интересов друг друга и лиц, обвиняемых в совершении преступления, не создавая при этом препятствий для процессуальной деятельности другой стороны.

Обеспечению конституционного принципа состязательности и равноправия сторон способствует положение о непосредственности судебного разбирательства, закрепленное в ч. 1 ст. 240 УПК РФ и означающее, что все доказательства по уголовному делу подлежат непосредственному исследованию, суд заслушивает показания подсудимого, потерпевшего, свидетелей, заключение эксперта, осматривает вещественные доказательства, оглашает протоколы и иные документы, производит другие судебные действия по исследованию доказательств.

Следует отметить, что оглашение показаний, данных при производстве предварительного расследования, рассматривается как исключение и допускается лишь в случаях, предусмотренных законом (ч. 2 ст. 240 УПК РФ).
Между тем относительно необходимости применения данного института в литературе существует несколько позиций. В соответствии с первой позицией процедура оглашения показаний нарушает принцип равноправия сторон перед судом. Так, по мнению О.В. Уреновой, «отступление от непосредственности исследования в части возможности оглашения показаний лиц, даже в указанных в законе случаях, а в последующем возможность использовать эти показания в качестве доказательств нарушает принцип состязательности сторон, том числе равноправие сторон перед судом, так как при этом главным образом нарушается право лица, привлекаемого к уголовной ответственности» [3, с. 4]. Аналогичной позиции придерживается А. Клецкин, который указывает, что «если внимательно проанализировать положения УПК РФ, можно легко заметить, что они нарушают принципы равноправия и состязательности, согласно которым стороны наделены равными возможностями перед судом, в том числе правами по представлению доказательств, участию в их исследовании, заявлению ходатайств и отводов. При этом суд обязан обеспечивать справедливое и беспристрастное разрешение спора, предоставляя сторонам равные возможности для отстаивания своих позиций. Исходя из указанных принципов возможность реализации стороной своих прав и обязанностей не может зависеть от волеизъявления другой стороны» [4, с. 2].

Однако есть и другая точка зрения относительно оглашения показаний отсутствующих участников судопроизводства. К примеру, И.В. Руднев считает, что «оглашение показаний в ряде случаев может способствовать разрешению противоречий, которые возникают в ходе судебного следствия. Причем суд должен очень тщательно подойти к оценке показаний допрошенных лиц, данных ими как в суде, так и в ходе предварительного расследования» [5, с. 3]. А. Гринев, Г. Тарасова придерживаются этой же позиции, подчеркивая, что «аргументом в пользу допустимости оглашения в суде показаний потерпевшего и свидетеля вне зависимости от согласия сторон является необходимость оценки действий отказавшегося от дачи показаний потерпевшего или свидетеля, существенно изменившего показания, или при отсутствии оснований, предусмотренных ст. 51 Конституции РФ. В этой ситуации может быть поставлен вопрос о даче потерпевшим или свиде- 
телем заведомо ложных показаний суду или неправомерности его отказа от дачи показаний. Как известно, за такие действия предусмотрена уголовная ответственность. Поэтому должны быть, в том числе путем сопоставления показаний, выяснены причины противоречий, установлены причины отказа от дачи показаний. В результате возможен вывод о том, что существенное изменение показаний связано с добросовестным заблуждением потерпевшего или свидетеля. В других случаях может быть сделан вывод о заведомой ложности показаний или неправомерном отказе от их дачи» [6, с. 31].

Согласно позиции Конституционного Суда РФ, выраженной в Определении от 7 декабря 2006 г. № 548-О «По запросу Абинского районного суда Краснодарского края о проверке конституционности положений статьи 281 Уголовно-процессуального кодекса Российской Федерации и по жалобам граждан Фомина Дмитрия Евгеньевича, Шуленкова Александра Николаевича и Щербинина Алексея Валерьевича на нарушение их конституционных прав положениями той же статьи» [7], исключение из принципа непосредственности в виде возможности оглашения показаний свидетеля, потерпевшего обусловлено как необходимостью устранения неравенства в процессуальных возможностях по исследованию доказательств между стороной защиты и стороной обвинения, производившей допросы потерпевших и свидетелей в ходе досудебного производства и составившей соответствующие протоколы, так и стремлением создать для суда условия, при которых ему обеспечиваются свободные от постороннего влияния восприятие и оценка показаний участников уголовного судопроизводства. В тех же целях ста. 272 УПК РФ предусматривается, что при неявке кого-либо из участников уголовного судопроизводства суд выслушивает мнения сторон о возможности судебного разбирательства в его отсутствие и выносит определение или постановление об отложении судебного разбирательства или о его продолжении, а также о вызове или приводе неявившегося участника.

Созданию сторонам защиты и обвинения равных процессуальных возможностей по исследованию доказательств служит и закрепленное в ч. 1 ст. 281 УПК РФ правило, в силу которого оглашение ранее полученных показаний потерпевшего или свидетеля, не явившегося в судебное заседание, допускается только с согласия сторон, за исключением случаев, предусмотренных ч. 2 ст. 281 УПК РФ, когда обеспечить участие потерпевшего или свидетеля в судебном заседании не представляется возможным.

Вместе с тем представляется, что при решении вопроса об оглашении показаний отсутствующих свидетеля, потерпевшего у суда имеется определенная степень дискреции.

Суд как единственный носитель судебной власти обладает рядом исключительных полномочий в уголовном процессе: по рассмотрению и разрешению уголовных дел (ч. 1 ст. 29 УПК РФ), а также по принятию процессуальных решений, затрагивающих конституционные права и свободы личности (ч. 2 ст. 29 УПК РФ). При этом деятельность суда направлена на достижение назначения уголовного судопроизводства, закрепленного в ст. 6 УПК РФ: защиту прав и законных интересов лиц и организаций, потерпевших от преступлений; защиту личности от незаконного и необоснованного обвинения, осуждения, ограничения ее прав и свобод. Для реализации перечисленных целей и задач законодатель закрепил особые возможности суда, некоторые из которых имеют дискреционный характер. Они позволяют суду «применять на основе собственного внутреннего убеждения один из нескольких легитимных вариантов решения правовых вопросов в целях наиболее эффективного осуществления уголовного судопроизводства» [8, с. 9]. Такая деятельность суда характеризуется волевым моментом, формирующимся под влиянием внутреннего убеждения, мировоззрения, профессионального опыта, что является субъективной составляющей дискреционных полномочий. В то же время это не позволяет раскрывать понятие дискреционных полномочий через категории «субъективное право», «свобода», поскольку в отличие от субъективного права дискреция предполагает совершение действия (бездействия) не в личных интересах, а в интересах третьих лиц, общества, государства. Кроме того, действия и решения, принятые судом на основе предоставленных ему дискреционных полномочий, должны наиболее точно отвечать замыслу законодателя, соответствовать назначению уголовного процесса. Отсюда следует, что, с одной стороны, суд обязан использовать свою дискрецию лишь в рамках тех вариантов поведения, которые уже сосредоточены в праве, руководствуясь общими нормативными положениями, требованиями уголовнопроцессуальной формы, а с другой стороны, он может беспрепятственно пользоваться своими правовыми возможностями внутри установленных пределов. Как указывает К.М. Баева, уголовно-процессуальный закон изначально содержит «ряд норм, гипотезы которых направлены на отграничение допустимого усмотрения от злоупотребления правом при принятии прогностических, тактических решений в рамках производства по уголовному делу» [9, с. 96]. Помимо этого, деятельность властных субъектов находится под надзором и контролем вышестоящих государственных органов, т.е. они ответственны за свои действия (бездействие).

В целом наличие у суда дискреционных полномочий способствует обеспечению независимости, самостоятельности, беспристрастности судебной власти, а также позволяет восполнить пробелы в процессе правоприменительной деятельности в связи с невозможностью детально регламентировать все многообразие уголовно-процессуальных правоотношений [10, с. 395]. В то же время дискреция создает опасность чрезмерного усмотрения, злоупотреблений со стороны суда.

По своему содержанию злоупотребление дискреционными полномочиями представляет собой осуществление по своему усмотрению предоставленных законом возможностей в противоречии с их назначением, замыслом законодателя, результатом чего становится неоправданное ограничение или угроза нарушения конституционного права лица, вовлеченного в уголовное судопроизводство, либо такое ограничение прав и возможностей участника процесса, которое способно привести к нарушению права одного из субъектов на 
судебную защиту (в том числе вследствие нарушения права на судебное разбирательство в разумный срок) $[11$, c. 71]. Исходя из указанного определения, можно выделить следующие признаки злоупотребления дискреционными полномочиями. Во-первых, осуществление государственными органами и должностными лицами предоставленных им полномочий в противоречии с их назначением. Во-вторых, соответствие поведения властных субъектов правовым предписаниям и отсутствие нарушений уголовно-процессуального законодательства. В-третьих, причинение вреда правам и законным интересам участников процесса.

Представляется, что в некоторых случаях вышеперечисленные признаки наличествуют при оглашении судом показаний отсутствующих участников уголовного судопроизводства.

Если обратиться к судебной практике, то в Томской области при рассмотрении дел в суде первой инстанции довольно часто используется процедура оглашения показаний свидетеля, потерпевшего, подсудимого. Причинами этого являлись необходимость устранения противоречий в показаниях, неявка участника по уважительным причинам, его тяжелая болезнь или смерть.

Вместе с тем встречаются ситуации, в которых судья дал неверную оценку обстоятельствам, позволяющим огласить показания, чем нарушил права других субъектов уголовного судопроизводства.

Например, в ходе судебного разбирательства по делу № 10-11/2018 по ходатайству государственного обвинителя с согласия стороны защиты были оглашены показания свидетелей А. и Б., данные ими на предварительном следствии. При этом судьей при удовлетворении ходатайства не были уточнены основания для оглашения показаний, а также противоречия, которые государственный обвинитель посчитал существенными. После этого было удовлетворено ходатайство защитника об оглашении показаний свидетеля В., данных на предварительном следствии, без выяснения позиции по такому вопросу государственного обвинителя. А затем при отсутствии доказательств, свидетельствующих о принятых мерах по установлению места нахождения представителя потерпевшего и свидетелей и отрицательном результате таких мер, мировым судьей принимались решения об оглашении на основании п. 5 ч. 2 ст. 281 УПК РФ данных на предварительном следствии показаний представителя потерпевшего Г., свидетелей Д., Е., Ж. по ходатайствам государственного обвинителя с согласия стороны защиты [12].

Видится, что в ходе разбирательства по данному уголовному делу судья ограничился согласием сторон на оглашение показаний отсутствующих участников уголовного судопроизводства без исследования соответствующих оснований. В таких действиях мирового судьи можно наблюдать злоупотребление дискреционными полномочиями, которое прямо не противоречит предписаниям уголовно-процессуального законодательства, однако не соответствует назначению уголовного судопроизводства, принципу состязательности и нарушает права и законные интересы участников процесса. К таким выводам пришел и Советский районный суд г. Томска при пересмотре дела в порядке апелляционного судопроизводства.
В качестве примера можно также привести обстоятельства, установленные в ходе производства по кассационной жалобе потерпевшего Н., в которой он выразил несогласие с состоявшимися по делу судебными решениями [13]. В судебном разбирательстве по делу № 44y-9/2017 потерпевший и его представитель не смогли принять участие, о чем предварительно уведомили суд и заявили ходатайство об отложении судебного разбирательства. Однако мировой судья отказал в удовлетворении данного ходатайства и рассмотрел уголовное дело в ранее назначенный день без их участия. В отсутствие потерпевшего по инициативе государственного обвинителя было принято решение об оглашении показаний свидетелей Ц., Э., Д., на основании которых суд пришел к выводу о том, что потерпевший совершил «противоправные и аморальные действия», послужившие поводом для посягательства на его здоровье. При рассмотрении уголовного дела судом не были предприняты меры к вызову отсутствующих участников, что свидетельствовало о злоупотребительном поведении мирового судьи и стало основанием для отмены приговора мирового судьи и передачи материалов дела на новое рассмотрение.

Следует отметить, что вопрос об оглашении показаний, процессуальном равноправии сторон и состязательности регламентирован и в международных актах. $\mathrm{B}$ соответствии с положениями Международного пакта о гражданских и политических правах (подп. «е» п. 3 ст. 14) и Конвенции о защите прав человека и основных свобод (подп. «d» п. 3 ст. 6) одним из обязательных условий справедливого судебного разбирательства является право обвиняемого «допрашивать показывающих против него свидетелей или иметь право на то, чтобы эти свидетели были допрошены, и иметь право на вызов и допрос свидетелей в его пользу на тех же условиях, что и для свидетелей, показывающих против него» [14]. Исходя из этого, при отсутствии соответствующих гарантий оглашение показаний неявившихся участников судебного разбирательства нарушает не только принцип состязательности, но и общепризнанные права человека.

Для определения справедливости судебного разбирательства при оглашении показаний свидетеля, потерпевшего ЕСПЧ рассматривает дела на основе теста, выработанного в Постановлении Большой Палаты Европейского Суда по делу «Перна против Италии» (Perna v. Italy; жалоба № 48898/99, § 29, ECHR 2003-V) [15]. Среди критериев законности и обоснованности оглашения показаний были выделены: а) обоснованность ходатайства подсудимого о возражении относительно оглашения показаний, его относимость к сути обвинения и способность привести к оправданию заявителя; б) наличие или отсутствие нарушений суда первой инстанции, который не обеспечил явку в суд конкретного свидетеля для дачи показаний в пользу подсудимого, его права, гарантированного подп. «d» п. 3 ст. 6 Конвенции; в) наличие иных доказательств по делу; г) возможность подсудимого прокомментировать оглашенные показания, так же как и другие доказательства.

Следует подчеркнуть, что ЕСПЧ расценивает отсутствие возражений подсудимого относительно оглашения показаний как отказ от права только в случае, если 
он был заявлен недвусмысленно и сопровождался минимальными гарантиями, соразмерными с его значимостью. Отказ необязательно должен быть явным, но он должен быть добровольным и представлять собой осознанный и разумный отказ от права, включать в себя демонстрацию подсудимым того, что он мог разумно предвидеть последствия своего поведения. Кроме того, такой отказ не должен противоречить каким-либо важным общественным интересам.

В Постановлении по делу «Макеев (Makeyev) против России» (жалоба № 13769/04) [16] ЕСПЧ изучил: являлось ли отсутствие возражений огласить показания свидетелей отказом от права на их допрос в судебном заседании; были ли их показания решающими для дела и приняли ли власти достаточные меры для того, чтобы обеспечить явку свидетелей в суд. В результате исследования этих вопросов ЕСПЧ пришел к выводу об отсутствии адекватных мер для обеспечения явки свидетелей в судебное заседание, а также о невозможности подсудимого поучаствовать в допросе трех свидетелей, показания которых имели решающее значение по делу.

Необходимо обратить внимание, что в российской судебной практике встречаются положительные примеры полного, обоснованного исследования обстоятельств дела, позволяющих решить вопрос об оглашении показаний отсутствующих участников уголовного судопроизводства. Так, в судебном разбирательстве по уголовному делу № 22-2098/2018 [17] судья для оглашения показаний потерпевшей при наличии возражений со стороны подсудимого и его защитника предварительно установил невозможность потерпевшей явиться в су- дебное заседание ввиду тяжелой болезни и нетранспортабельности, а также наличие возможности стороны защиты оспорить ее показания иными способами, которые не были использованы.

На основе вышеизложенного можно прийти к выводу, что в некоторых ситуациях оглашение показаний отсутствующих в судебном разбирательстве участников допустимо, но только в случаях, когда нет иного способа получить необходимую информацию по делу. К таким случаям можно отнести: необходимость разрешения некоторых противоречий, возникших в результате судопроизводства, установление правдивости данных показаний путем их сравнения и анализа. В то же время оглашение показаний противоречит принципам состязательности и непосредственности, что может привести к нарушению прав участников уголовного судопроизводства, постановлению незаконного и необоснованного приговора. Для предотвращения возникновения данной ситуации, предупреждения злоупотребительного поведения со стороны судьи при решении вопроса об оглашении показаний неявившихся участников уголовного судопроизводства, необходимо закрепить в УПК РФ механизм реализации института оглашения показаний при одновременном установлении гарантий для участников уголовного судопроизводства. К числу гарантий можно отнести: определение судом достоверности оснований для оглашения показаний; принятие мер для вызова отсутствующих участников уголовного процесса; обеспечение субъектам уголовного судопроизводства иных правовых возможностей для исследования доказательств и оспаривания оглашенных показаний.

\section{ЛИТЕРАТУРА}

1. Строгович М.С. Курс советского уголовного процесса. М. : Наука, 1968. Т. 1.470 с.

2. По делу о проверке конституционности отдельных положений статей 7, 15, 107, 234 и 450 Уголовно-процессуального кодекса Российской Федерации в связи с запросом группы депутатов Государственной Думы : постановление Конституционного Суда РФ от 29.06.2004 № 13-П// Рос. газ. 2004. 7 июля. № 143.

3. Уренева O.В. Принцип состязательности сторон и оглашение в судебном заседании показаний лиц, данных при производстве предварительного расследования или ранее данных в судебном заседании // Российский судья. 2003. № 3. С. 3-6.

4. Клеикин А. Оглашение показаний не явившихся в суд потерпевших и свидетелей // Законность. 2005. № 10. С. 38-39.

5. Руднев В.И. Оглашение в суде показаний подсудимых, а также потерпевших и свидетелей, ранее данных ими при производстве предварительного расследования // Комментарий судебной практики. 2010. Вып. 15. С. 187-196.

6. Гринев А., Тарасова Г. Возможность оглашения прежних показаний в суде // Законность. 2003. № 6. С. 30-31.

7. По запросу Абинского районного суда Краснодарского края о проверке конституционности положений статьи 281 Уголовно-процессуального кодекса Российской Федерации и по жалобам граждан Фомина Дмитрия Евгеньевича, Шуленкова Александра Николаевича и Щербинина Алексея Валерьевича на нарушение их конституционных прав положениями той же статьи : определение Конституционного Суда РФ от 07.12.2006 № 548-О // СПС Консультант-Плюс (дата обращения: 23.10.2019).

8. Пронин К.В. Дискреционные полномочия суда в уголовном судопроизводстве : автореф. ... дис. канд. юрид. наук. Челябинск, 2010. $25 \mathrm{c}$.

9. Баева К.М. Субъекты злоупотребления правом в уголовном судопроизводстве // Судебная власть и уголовный процесс. 2017. № 3. C. 94-99.

10. Raimondo F.O. General Principles of Law as Applied by International Criminal Courts and Tribunals // The Law and Practice of International Courts and Tribunals. 2007. Vol. 6, is. 3. P. 393-407.

11. Трубникова Т.В. Злоупотребление правом в уголовном процессе: критерии и пределы вмешательства со стороны государства // Вестник Томского государственного университета. Право. 2015. № 3 (17). С. 65-78.

12. Уголовное дело № 10-11/2018 // Архив Советского районного суда г. Томска.

13. Уголовное дело № 44y-9/2017 // Архив Томского областного суда.

14. Конвенция о защите прав человека и основных свобод (заключена в Риме 04.11.1950; с изм. от 13.05.2004) // СПС Консультант-Плюс (дата обращения: 23.10.2019).

15. Постановление Большой Палаты Европейского Суда по делу «Перна против Италии» (Perna v. Italy; жалоба № 48898/99, $\S$ 29, ECHR 2003-V) // Гарант.ру : информационно-правовой портал (дата обращения: 24.10.2019). 
16. Постановление Европейского Суда по правам человека по делу «Макеев (Makeyev) против России» (жалоба № 13769/04) // Российская хроника Европейского Суда. 2010. № 4.

17. Уголовное дело № 22-2098/2018 // Архив Томского областного суда.

Disclosure of Evidence as Possibility to Abuse Discretionary Powers by Courts Ugolovnaya yustitsiya - Russian Journal of Criminal Law, 2019, no. 14, pp. 45-50. DOI 10.17223/23088451/14/10

Olga V. Zheleva, Tomsk State University (Tomsk, Russian Federation). E-mail: zheleva.olga@ gmail.com

Keywords: criminal proceedings, participants in criminal proceedings, disclosure of evidence, abuse of discretionary powers.

The article focuses on the legal capabilities of participants in criminal proceedings and the powers of judges in resolving the issue of evidence disclosure. The disclosure of evidence of a witness, a victim, and a defendant is an exception to the principle of immediacy, so its incorrect application risks a violation of the rights and legitimate interests of participants in the process, as well as the adoption of an illegal and unreasonable decision on the case. The author argues that in some cases the disclosure of evidence is a way of abuse of discretion by the court. In this regard, the following tasks are solved: 1) definition of the evidence disclosure institution; 2) definition of the court discretionary powers; 3 ) determination of abuse of discretionary powers as a separate type of behaviour; 4) identification of cases of discretionary power abuse by courts in evidence disclosure; 5) definition of criteria for the legitimate and reasonable disclosure of evidence of absent participant in a process. The research employs general and specific scholarly methods of cognition: dialectical, formal logical, comparative legal, systemic, analysis and synthesis. The author analyses the procedure for evidence disclosure in case of absent participants in the process, as enshrined in the current criminal procedure legislation and indicates various positions regarding the need to disclose evidence. The disclosure of evidence can help resolve conflicts. However, this procedure contradicts the principles of adversarial and equal rights of the parties. The study of ECHR resolutions and decisions of Russian courts has revealed a number of cases when the courts incorrectly and insufficiently established the necessity of applying the disclosure of evidence. As a result, the operation of the court can be regarded as an abuse of discretionary powers, which led to an illegal sentence and violation of the rights of participants in criminal proceedings. The author defines the concept and signs of abuse of discretionary powers by courts when the evidence of absent participants is disclosed. The legality and validity of evidence disclosure can be guaranteed through determining reliable grounds for evidence disclosure; taking measures to call absent participants in the criminal process to court; ensuring the implementation of other legal possibilities for examining evidence and challenging the testimony.

\section{References}

1. Strogovich, M.S. (1968) Kurs sovetskogo ugolovnogo protsessa [The Soviet Criminal Process]. Vol. 1. Moscow: Nauka.

2. The Constitutional Court of the Russian Federation. (2004) Postanovlenie Konstitutsionnogo Suda RF ot 29.06.2004 № 13-P “Po delu o proverke konstitutsionnosti otdel'nykh polozheniy statey 7, 15, 107, 234 i 450 Ugolovno-protsessual'nogo kodeksa Rossiyskoy Federatsii v svyazi s zaprosom gruppy deputatov Gosudarstvennoy Dumy" [Resolution No. 13-P of the Constitutional Court of the Russian Federation of June 29, 2004, "On constitutionality of certain provisions of Articles 7, 15, 107, 234 and 450 of the Code of Criminal Procedure of the Russian Federation in connection with the request of a group of deputies of the State Duma"]. Rossiyskaya gazeta. 7th July.

3. Ureneva, O.V. (2003) Printsip sostyazatel'nosti storon i oglashenie v sudebnom zasedanii pokazaniy lits, dannykh pri proizvodstve predvaritel'nogo rassledovaniya ili ranee dannykh v sudebnom zasedanii [The principle of adversariality of the parties and disclosure of evidence, given during the preliminary investigation or earlier, at the hearing]. Rossiyskiy sud'ya - Russian Judge. 3. pp. 3-6.

4. Kletskin, A. (2005) Oglashenie pokazaniy ne yavivshikhsya v sud poterpevshikh i svideteley [Disclosure of evidence of victims and witnesses who did not appear in court]. Zakonnost'. 10. pp. 38-39.

5. Rudnev, V.I. (2010) Oglashenie v sude pokazaniy podsudimykh, a takzhe poterpevshikh i svideteley, ranee dannykh imi pri proizvodstve predvaritel'nogo rassledovaniya [The disclosure in court of evidence of defendants, victims, and witnesses, given during the preliminary investigation]. Kommentariy sudebnoy praktiki. 15. pp. 187-196.

6. Grinev, A. \& Tarasova, G. (n.d.) Vozmozhnost' oglasheniya prezhnikh pokazaniy v sude [The possibility of disclosing previous evidence in court]. Zakonnost'. 6. pp. 30-31.

7. The Constitutional Court of the Russian Federation. (2006) Decision No. 548-O of the Constitutional Court of the Russian Federation of December 7, 2006, "At the request of the Abinsk District Court of Krasnodar Territory on the constitutionality of provisions of Article 281 of the Code of Criminal Procedure of the Russian Federation and on complaints from citizens Fomin Dmitry Evgenievich, Shulenkov Alexander Nikolaevich, and Shcherbinin Alexey Valerievich on violation of their constitutional rights by the provisions of the aforementioned article. [Online] Available from: http://www.consultant.ru/document/cons_doc_LAW_66501/. (Accessed: 23rd October 2019). (In Russian).

8. Pronin, K.V. (2010) Diskretsionnye polnomochiya suda v ugolovnom sudoproizvodstve [Discretionary powers of the court in criminal proceedings]. Abstract of Law Cand. Diss. Chelyabinsk.

9. Baeva, K.M. (2017) Sub"ekty zloupotrebleniya pravom v ugolovnom sudoproizvodstve [Subjects of abuse of law in criminal proceedings]. Sudebnaya vlast' i ugolovnyy protsess - Judicial Authority and Criminal Process. 3. pp. 94-99.

10. Raimondo, F. (2007) General Principles of Law as Applied by International Criminal Courts and Tribunals. The Law and Practice of International Courts and Tribunals. 6(3). pp. 393-407. DOI: 10.1163/156918507X262972

11. Trubnikova, T.V. (2015) Abuse of right in criminal proceeding: criteria and state interference limits. Vestnik Tomskogo gosudarstvennogo universiteta. Pravo - Tomsk State University Journal of Law. 3(17). pp. 65-78. (In Russian).

12. The Archive of the Soviet District Court of Tomsk. (2018) Criminal Case No. 10-11 / 2018.

13. The Archive of the Tomsk Regional Court. (2017) Criminal case No. 44u-9/2017.

14. The European Union. (n.d.) Konventsiya o zashchite prav cheloveka i osnovnykh svobod (Zaklyuchena v g. Rime 04.11.1950) (s izm. ot 13.05.2004) [Convention for the Protection of Human Rights and Fundamental Freedoms (signed in Rome on April 4, 
1950) (as amended on May 13, 2004)]. [Online] Available from: http://www.consultant.ru/document/cons_doc_LAW_29160/. (Accessed: 23rd October 2019)

15. The ECHR. (n.d.) Postanovlenie Bol'shoy Palaty Evropeyskogo Suda po delu «Perna protiv Italii» (Perna v. Italy) (zhaloba № 48898/99, § 29, ECHR 2003-V) [Resolutiont of the Grand Chamber in Perna v. Italy (Perna v. Italy) (Complaint No. 48898/99, $\S 29$, ECHR 2003-V)]. [Online] Available from:Garant.ru. (Accessed: 24th October 2019).

16. The ECHR. (n.d.) Postanovlenie Evropeyskogo Suda po pravam cheloveka po delu "Makeev (Makeyev) protiv Rossii" (zhaloba № 13769/04) [Resolution of the European Court of Human Rights in Makeyev v. Russia (Complaint No. 13769/04)]. Rossiyskaya khronika Evropeyskogo Suda. 4.

17. The Archive of the Tomsk Regional Court. (2018) Criminal Case No. 22-2098 / 2018. 